\title{
Static analysis of mono leaf spring with different composite materials
}

\author{
B. Raghu Kumar ${ }^{1}$, R. Vijaya Prakash ${ }^{2 \star}$ and N. Ramesh ${ }^{3}$ \\ ${ }^{1}$ Department of Mechanical Engineering, Koneru Lakshmaiah University, Vijayawada, Andhra Pradesh, India. \\ ${ }^{2}$ College of Engineering and Technology, Acharya Nagarjuna University, Andhra Pradesh, India. \\ ${ }^{3}$ Department of Mechanical Engineering, Koneru Lakshmaiah University, Vijayawada, Andhra Pradesh, India.
}

Accepted 8 January, 2013

\begin{abstract}
In the present scenario, composites are widely used in most of the industries in place of steel, due to low weight to strength ratio. In automobile industry, one can think of replacing parts with composites. The aim of this paper is to suggest the best composite material for design and fabrication of complete mono composite leaf spring. A single leaf with variable thickness and variable width for constant cross sectional area of different composite materials, with similar mechanical and geometrical properties to the multi leaf spring, were modeled and analyzed. The finite element results using ANSYS software showing stresses and deflections were verified with analytical results. The design constraints were stresses and displacement. Compared to the steel spring, the composite spring has stresses and deflection that are much lower, and the spring weight is nearly $\mathbf{7 8 \%}$ lower.
\end{abstract}

Key words: Leaf spring, composite, steel spring.

\section{INTRODUCTION}

Composite materials consist of two or more physically distinct and mechanically separable components called reinforcement and matrix. These two components can be mixed in a controlled way to achieve optimum properties, which are superior to the properties of each individual component. Composite materials have been widely used in automobile industry because of its high strength and modulus to weight ratio, low cost and flexibility in material and structure design. The suspension leaf spring is one of the potential items for weight reduction in automobile as it accounts for ten to twenty percent of the unsprung weight. This helps in achieving the vehicle with improved riding qualities. Since the strain energy in the spring is inversely proportional to density and young's modulus of the material, it is always suggested that the material for leaf spring must have low density and modulus of elasticity. Composite materials are having such properties as compared to the conventional steel.

The introduction of composite materials made it possible to reduce the weight of the leaf spring with out

\footnotetext{
${ }^{*}$ Corresponding author. E-mail: rvyadavvignan@gmail.com.
}

any reduction on load carrying capacity and stiffness; since the composite materials have more elastic strain energy storage capacity and high strength-to-weight ratio as compared to those of steel.

Several papers were devoted to the application of composite materials for automobiles. Rajendran and Vijayarangan $(2001,2002)$ studied the application of composite structures for automobiles and design optimization of a composite leaf spring. Great effort has been made by the automotive industries in the application of leaf springs made from composite materials (Daugherty, 1981; Dharam, 1978). Vijayarangan and Ganesan (1994) showed the introduction of fiber reinforced plastics (FRP) which made it possible to reduce the weight of a machine element without any reduction of the load carrying capacity. Because of FRP materials high elastic strain energy storage capacity and high strength-to-weight ratio compared with those of steel, multi-leaf steel springs are being replaced by mono leaf FRP springs (Tanabe et al., 1982; Yu and Kim, 1998). Shankar and Vijayarangan (2006) has fabricated and tested the Glass fiber/Epoxy leaf spring with and without bonded end joints and said that around $85 \%$ of weight has been reduced. 
Table 1. Parameters at center and end points for composite leaf spring.

\begin{tabular}{lcc}
\hline Parameter & At center & At end \\
\hline Breadth (in $\mathrm{mm}$ ) & 50 & 62 \\
Thickness (in mm) & 125 & 25 \\
\hline
\end{tabular}

Table 2. Material properties of different composites.

\begin{tabular}{ccccccc}
\hline Material properties & Steel & E Glass Epoxy & Graphite Epoxy & Boron Aluminum & Carbon Epoxy & Kevlar Epoxy \\
\hline $\mathrm{E}_{11}$ & $2 \times 10^{5}$ & 34 & 142.6 & 215 & 142 & 80 \\
$\mathrm{E}_{22}$ & $2 \times 10^{5}$ & 65.3 & 96.0 & 144.1 & 98.1 & 55 \\
$\mathrm{G}_{12}$ & $77 \times 10^{3}$ & 24.33 & 6.00 & 57.2 & 6.57 & 2.2 \\
$\mathrm{G}_{23}$ & $77 \times 10^{3}$ & 16.98 & 3.10 & 45.9 & 3.77 & 1.8 \\
$\mathrm{~V}_{12}$ & 0.3 & 0.217 & 0.25 & 0.19 & 0.3 & 0.34 \\
$\mathrm{~V}_{23}$ & 0.3 & 0.366 & 0.35 & 0.29 & 0.34 & 4 \\
\hline
\end{tabular}

The spring was thicker at the center and has varying thickness along its length (Grip et al., 1986). At least the main leaf of which is design in such manner that the cross sectional moment of inertia of the leaf varies in the longitudinal direction of the spring, so that the bending stress in the leaf will be essentially equal over the major portion of the length of the spring (Ingvarsson and Raattamaa, 1997). The prior cracking in the spring was extensive enough to reduce the strength of the spring to the point where normal dirt road forces were adequate to produce rupture (Clarke and Borowski, 1996). Patunkar showed that under the same static load conditions deflection and stresses of steel leaf spring and composite leaf spring are found with the great difference. Deflection of composite leaf spring is less as compared to steel leaf spring with the same loading condition (Patunkar, 2011). Senthil Kumar (2007) showed that composite leaf spring is found to have lesser stress, higher stiffness and higher natural frequency than that of existing steel leaf spring.

\section{Specification of the problem}

The objective of the present work is to suggest a best available composite material for design, fabricate complete composite mono leaf spring.

\section{DESCRIPTION ON THE DIMENSIONS OF THE LEAF SPRING}

Leaf springs are subjected to different types of loading. By considering all the types of loads various kinds of composite leaf spring have been developed.

In this paper, only a mono-leaf composite leaf spring with varying width and varying thickness with uniform cross section is designed. The dimensions are calculated from the basic equations of leaf spring from strength point of view and stiffness point of view. The results showed that a spring width decreases hyperbolically and thickness increases linearly from the spring eyes towards the axle seat. The parameters of composite leaf spring are shown in Table 1.

\section{Material properties}

Materials properties of different materials used in this work are listed in the Table 2.

\section{Finite element analysis (FEA) of mono composite leaf spring}

To design steel leaf spring, a stress analysis was performed using the finite element method done using ANSYS software. Modeling was done for every leaf with eight-node 3D brick element (solid 45) and five-node 3D contact element (contact 49) used to represent contact and sliding between adjacent surfaces of leaves. Also, analysis carried out for composite leaf spring for Glass/Epoxy, Graphite/Epoxy, Carbon/Epoxy, Kevlar epoxy, Boron Aluminum composite materials and the results were compared with steel leaf spring. The maximum deflection and shear stresses along the adhesive layer were measured. Figures 2 to 13 show the FEA results for steel and composite mono leaf spring (Glass/Epoxy, Carbon/Epoxy, Graphite/Epoxy, Kevlar epoxy and Boron Aluminum). A comparison graph of deflections and stresses among all the composites and steel are shown in the Figure 14.

\section{RESULTS AND DISCUSSION}

FEA results of the leaf springs under static loading 


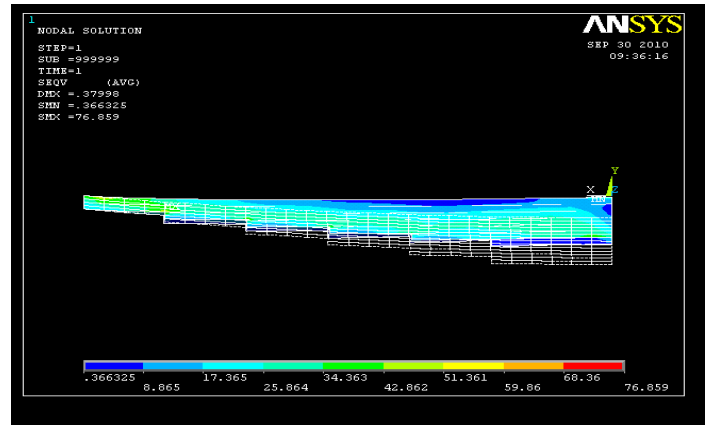

Figure 1. Displacement pattern for steel leaf spring.

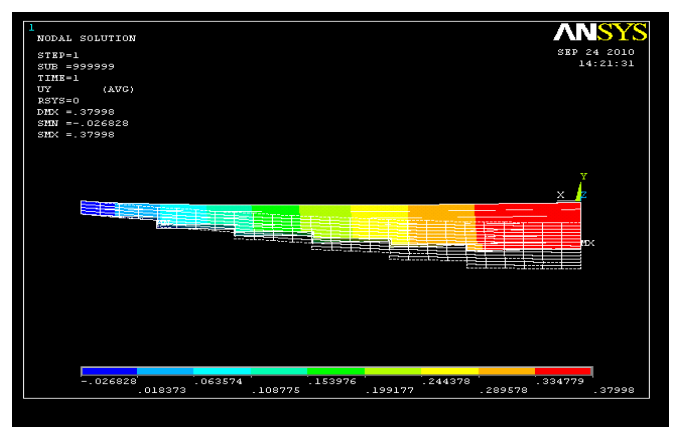

Figure 2. Stress pattern for steel leaf spring.

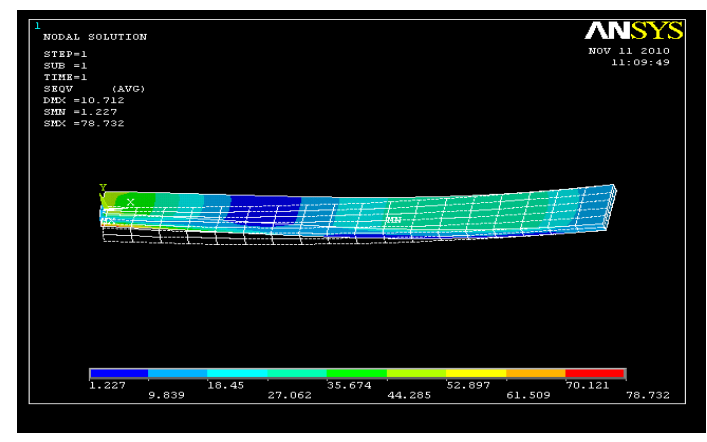

Figure 3. Displacement pattern for E-Glass/Epoxy.

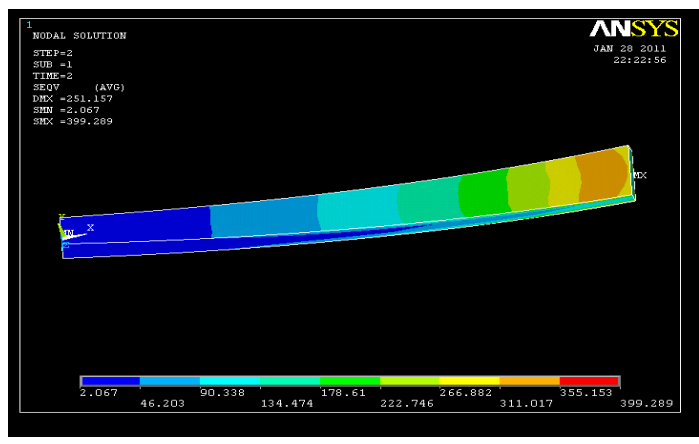

Figure 4. Stress pattern for E-Glass/Epoxy.

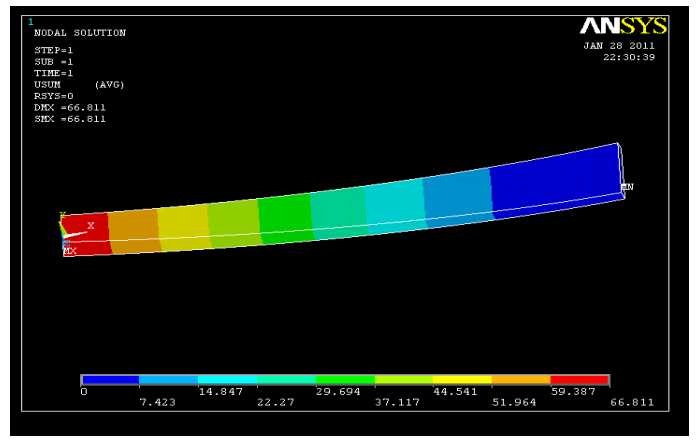

Figure 5. Displacement pattern for Graphite Epoxy.

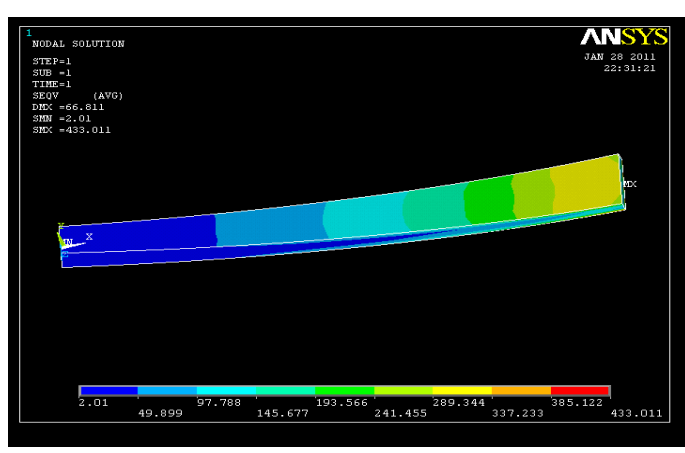

Figure 6. Stress pattern for Graphite Epoxy.

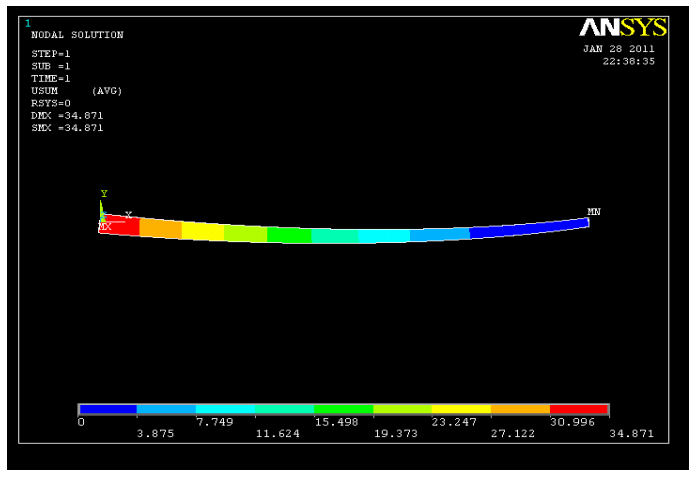

Figure 7. Displacement pattern for Boron Aluminum.

containing the stresses and deflection are listed in the Table 3. Figure 1 represents the deflection pattern and Figure 2 represents the stress distribution of Steel leaf spring. Figure 3 to 12 show the maximum deflection and maximum stress values for different composite materials and these values are tabulated in the Table 3 .

We can observe from Table 3 that there is a much weight reduction for composites materials compared to steel. For E Glass Epoxy 88.4\%, Graphite Epoxy 92.4\%, Boron Aluminum 90.3\%, Carbon Epoxy 92.3\%, and 


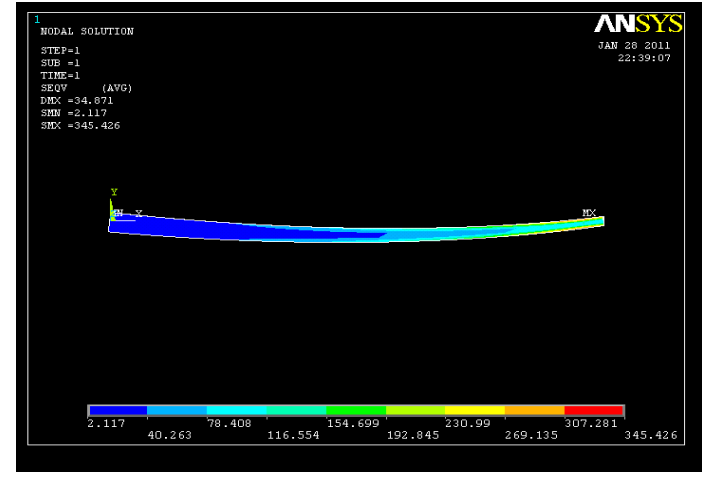

Figure 8. Stress pattern for Boron Aluminum

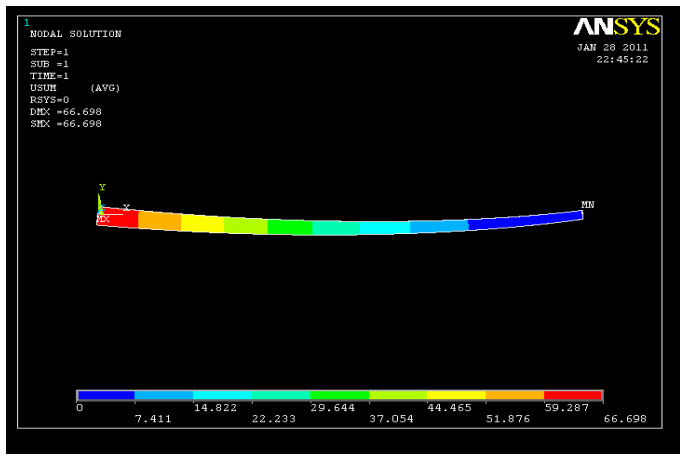

Figure 9. Displacement pattern for Carbon Epoxy.

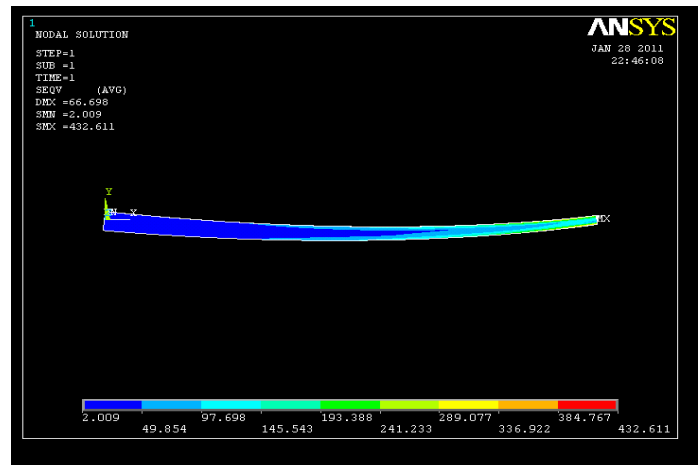

Figure 10. Stress pattern for Carbon Epoxy.

Kevlar Epoxy $85.11 \%$ savings in the weight as compared to steel.

From Table 3 we can observe that all the composites are not suitable for replacing the steel in the manufacturing of the leaf spring. E Glass epoxy and Kelvar epoxy are deflecting more compared to steel. If the space is a limiting criterion these composites may not be the suitable materials for replacing the steel. But the Graphite epoxy, Boron Aluminum and Carbon epoxy are

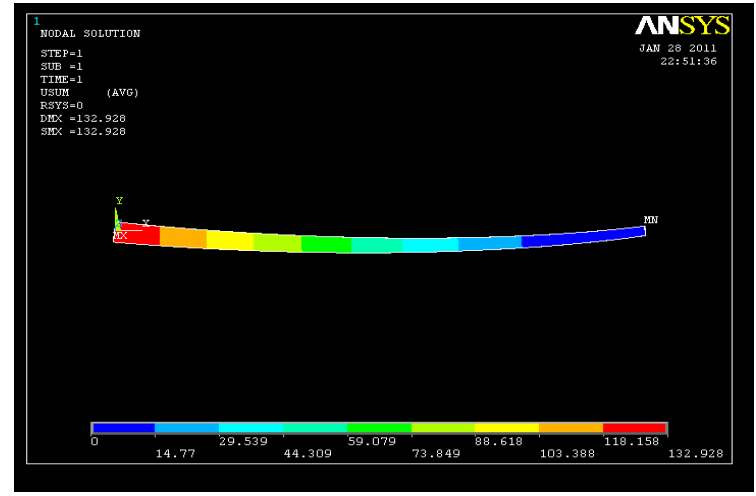

Figure 11. Displacement pattern for Kevlar Epoxy.

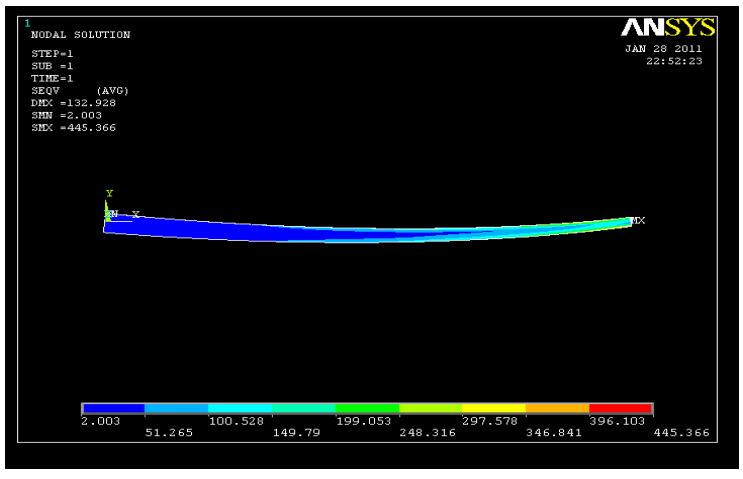

Figure 12. Stress pattern for Kevlar Epoxy.

suitable materials for this application. From the Figure 13 we can observe that the deflection is minimum for Boron Aluminum as compared to remaining composite materials.

From Table 3 we can also observe that Graphite Epoxy, Carbon Epoxy, Kevlar Epoxy are getting more stress as compared to the steel. These materials may with stand with theses stresses but from stress point of view, these materials may not be the suitable materials for replacing the steel. But, E Glass Epoxy and Boron Aluminum are getting less stresses as compared to the steel. From the Figure 14 we can say that Boron Aluminum is getting very less stress as compared to the remaining materials.

Shankar (Shankar and Vijayarangan 2006) has proved experimentally that composites leaf springs can bear the load. The composite spring is designed for same stiffness as that of steel leaf spring; both the springs are considered to be almost equal in vehicle stability. So, the steel leaf spring was replaced with a composite. The objective was to obtain a spring with minimum weight which is capable of carrying a given static external forces by constraints limiting stresses and displacements. Thus, the objective of the unsprung mass is achieved to a 
Table 3. Comparison results of deflection and stress.

\begin{tabular}{clccc}
\hline S/ No & Material & Max deflection $(\mathbf{m m})$ & Max stress (MPa) & Weight $(\mathbf{K g})$ \\
\hline 1 & Steel & 77 & 425.17 & 26 \\
2 & E Glass Epoxy & 79 & 400.15 & 3.02 \\
3 & Graphite Epoxy & 66.91 & 433.91 & 1.97 \\
4 & Boron Aluminum & 35.97 & 345.78 & 2.52 \\
5 & Carbon Epoxy & 66.69 & 432.51 & 2.01 \\
6 & Kevlar Epoxy & 82.1 & 439.15 & 3.87 \\
\hline
\end{tabular}

Max deflection( $\mathrm{mm}$ )

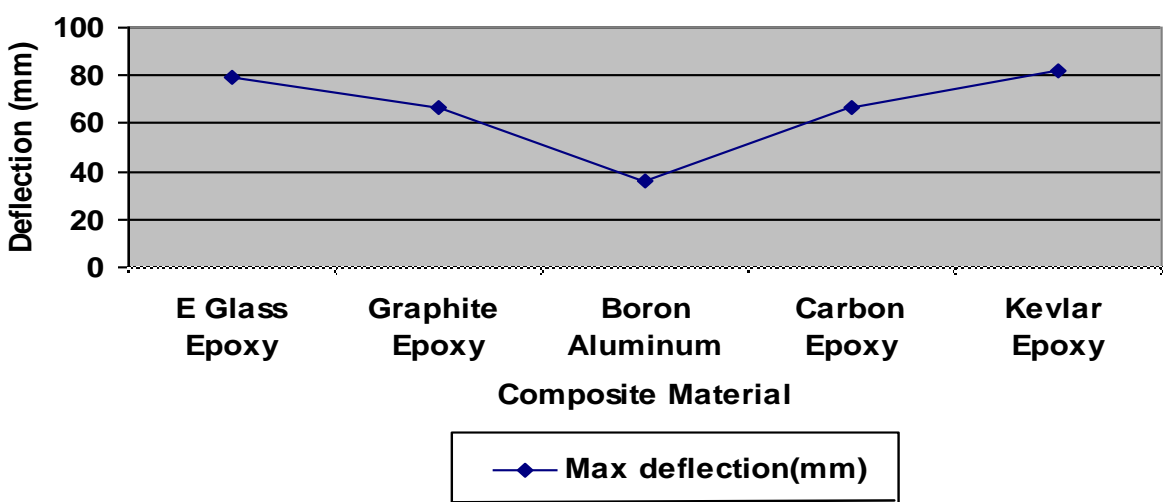

Figure 13. Maximum deflection distribution graph.

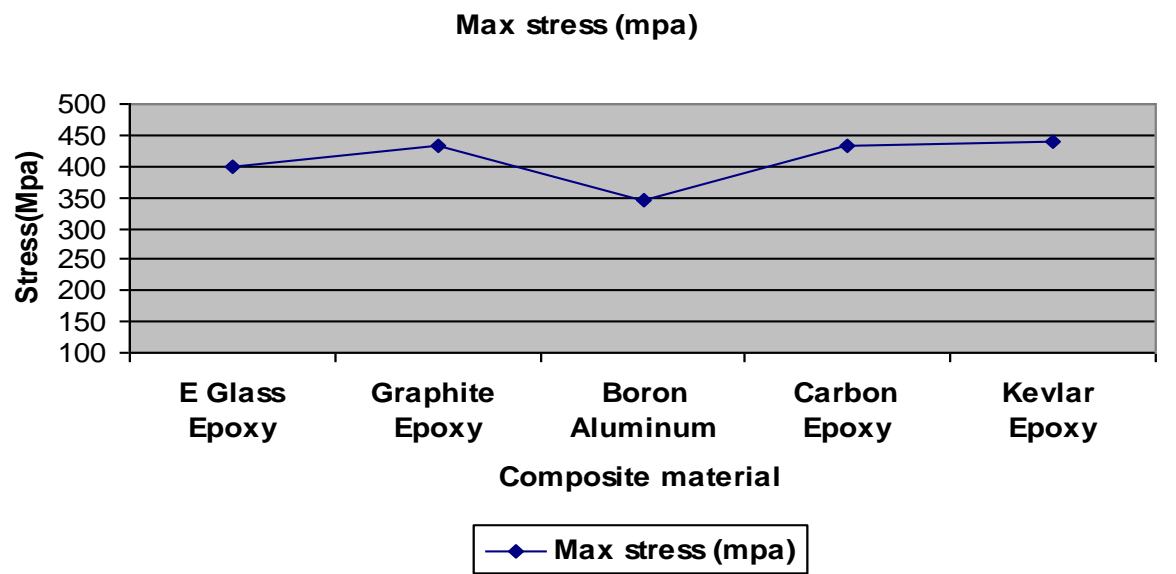

Figure 14. Maximum stress distribution graph.

larger extent.

\section{CONCLUSION}

Composite springs with varying width and thickness and constant cross section has been developed. These leaf springs are analyzed in ANSYS software with different composite materials along with the steel. A comparative study has been made between different composite materials and with the steel in respect of weight, deflection and stress. It can be observed that Boron Aluminum is the best suitable material for replacing the steel in manufacturing of mono leaf spring. The savings 
in the weight is $90.3 \%$

\section{REFERENCES}

Clarke CK, Borowski GE (1996). Evaluation of a Leaf Spring Failure ASM, International, Materials Park, OH, pp. 622-625.

Daugherty RL (1981). Composite Leaf Springs in Heavy Truck Applications. K. Kawata, T.Akasaka (Eds). Composite Materials Proceedings of Japan-US Conference Tokyo pp. 529-538.

Dharam CK (1978). Composite Materials Design and Processes for Automotive Applications. The ASME Winter Annual Meeting, San Francisco pp. 19-30.

Grip CE, Hagstad BJ, Andersson BH (1986). Spring steel. United States Patent, 4575912.

Ingvarsson H, Raattamaa JR (1997). Leaf spring for a rigid axle of a vehicle, United States Patent, 5683076

Patunkar MM (2011). Modeling and Analysis of Composite Leaf Spring under the Static Load Condition by using FEA. Int. J. Mech. Ind. Eng. $1: 1$.

Rajendran I, Vijayarangan S (2001). Optimal Design of a Composite Leaf Spring using Genetic Algorithms. Int. J. Comput. Struc. 79:11211129.
Rajendran I, Vijayarangan S (2002). Design and Analysis of a Composite Leaf Spring. J. Institute Eng. India 82:180-187.

Senthil Kumar M (2007).Static analysis and fatigue life prediction of steel and composite leaf spring for light weight vehicles. J. Sci. Ind. Res. 66.

Shankar GSS, Vijayarangan S (2006). Mono Composite Leaf Spring For Light Weight Vehicle - Design, End Joint Analysis And Testing. Mater. Sci. 12(3):220-225.

Tanabe K, Seino T, Kajio Y (1982). Characteristics of Carbon/Glass Fiber Reinforced Plastic Leaf Spring, SAE820403 pp. 1628-1634.

Vijayarangan S, Ganesan N (1994). Static Stress Analysis of a Composite Bevel Gear using a Three-dimensional Finite Element Method. Comput. Struc. 51(6):771-783.

Yu WJ, Kim HC (1998). Double Tapered FRP Beam for Automobile Suspension Leaf Spring. Comp. Struc. pp. 279-300. 